This item was submitted to Loughborough's Research Repository by the author.

Items in Figshare are protected by copyright, with all rights reserved, unless otherwise indicated.

\title{
On the optimisation of road vehicle leading edge radius in varying levels of freestream turbulence
}

PLEASE CITE THE PUBLISHED VERSION

http://dx.doi.org/10.4271/2006-01-1029

PUBLISHER

(C) SAE International

VERSION

VoR (Version of Record)

LICENCE

CC BY-NC-ND 4.0

\section{REPOSITORY RECORD}

Newnham, Phil, Martin A. Passmore, and Anthony Baxendale. 2010. "On the Optimisation of Road Vehicle

Leading Edge Radius in Varying Levels of Freestream Turbulence”. figshare. https://hdl.handle.net/2134/6711. 


\section{On the Optimisation of Road Vehicle Leading Edge Radius in Varying Levels of Freestream Turbulence}

Phil Newnham, Martin Passmore and Jeff Howell Loughborough University

Anthony Baxendale MIRA Ltd.

Reprinted From: Vehicle Aerodynamics 2006 (SP-1991)

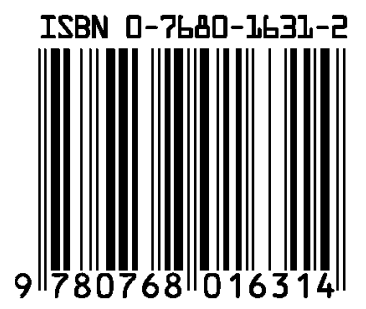


The Engineering Meetings Board has approved this paper for publication. It has successfully completed SAE's peer review process under the supervision of the session organizer. This process requires a minimum of three (3) reviews by industry experts.

All rights reserved. No part of this publication may be reproduced, stored in a retrieval system, or transmitted, in any form or by any means, electronic, mechanical, photocopying, recording, or otherwise, without the prior written permission of SAE.

For permission and licensing requests contact:

SAE Permissions
400 Commonwealth Drive
Warrendale, PA 15096-0001-USA
Email: permissions@ @ sae.org
Tel: $\quad 724-772-4028$
Fax: $\quad 724-776-3036$

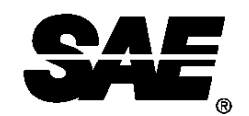

Global Mobility Database ${ }^{\circledast}$

All SAE papers, standards, and selected books are abstracted and indexed in the Global Mobility Database.

For multiple print copies contact:

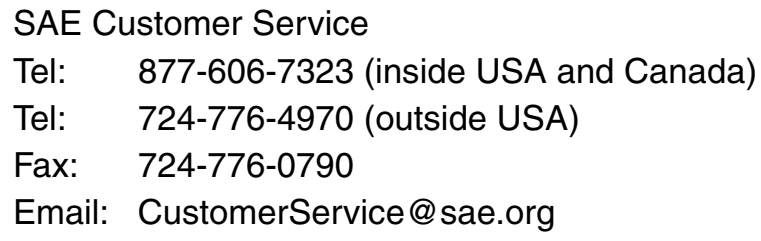

\section{ISSN 0148-7191}

\section{Copyright $\subset 2006$ SAE International}

Positions and opinions advanced in this paper are those of the author(s) and not necessarily those of SAE. The author is solely responsible for the content of the paper. A process is available by which discussions will be printed with the paper if it is published in SAE Transactions.

Persons wishing to submit papers to be considered for presentation or publication by SAE should send the manuscript or a 300 word abstract to Secretary, Engineering Meetings Board, SAE.

\section{Printed in USA}




\title{
On the Optimisation of Road Vehicle Leading Edge Radius in Varying Levels of Freestream Turbulence
}

\author{
Phil Newnham, Martin Passmore and Jeff Howell \\ Loughborough University \\ Anthony Baxendale \\ MIRA Ltd.
}

\begin{abstract}
It has been recognised that the ideal flow conditions that exist in the modern automotive wind tunnel do not accurately simulate the environment experienced by vehicles on the road. This paper investigates the effect of varying one flow parameter, freestream turbulence, and a single shape parameter, leading edge radius, on aerodynamic drag. The tests were carried out at model scale in the Loughborough University Wind Tunnel, using a very simple 2-box shape, and in the MIRA Full Scale Wind Tunnel using the MIRA squareback Reference Car. Turbulence intensities up to $5 \%$ were generated by grids and had a strong effect on transcritical Reynolds number and Reynolds sensitivity at both model scale and full scale. There was a good correlation between the results in both tunnels.
\end{abstract}

\section{INTRODUCTION}

It has always been the case that wind tunnel testing is only an approximation of the real world. Over recent decades wind tunnel engineers have added moving ground planes, boundary layer suction, adaptive walls, and other improvements to try to bring the wind tunnel model closer to the aerodynamic environment of the real car. Recently, more attention has been paid to modelling the turbulence environment of the real world, in the tunnel.

Real world ambient wind data are routinely collected for use by civil engineers, however much of this concentrates on wind velocities and turbulence at or above $10 \mathrm{~m}$. There are some data in the ESDU database [1] for as low as $3 \mathrm{~m}$, that show some interesting information, but it is not legitimate to simply extrapolate these data down to ground level. It is shown that increasing the roughness increases the turbulence intensity at $3 \mathrm{~m}$ from approximately $11 \%$ for the lowest roughness (snow covered farmland, flat arid desert) to more than $36 \%$ for the highest (city centres, forests) and trends are drawn of turbulence intensity and length scale. However, the length scale decreases with increasing roughness, from a maximum of $100 \mathrm{~m}$ down to just over $1 \mathrm{~m}$ at the highest roughness.

Richards et al. [2] investigated atmospheric turbulence closer to the ground. Their research was also aimed at structural engineering, but they were interested in the "wind loads on a variety of walls, fences and buildings". Measurements were taken for various heights from $0.115 \mathrm{~m}$ to $10 \mathrm{~m}$ using 3-component ultrasonic anemometers. Spectra and coherence information was published in order to compare data sampled at different frequencies and offer spectral models for the atmosphere at low levels. The results show that the turbulence spectra do vary significantly between $10 \mathrm{~m}$ and $1 \mathrm{~m}$. There is some small increase in the spectra for $\mathrm{u}$ and $\mathrm{v}$ components at frequencies between $0.01 \mathrm{~Hz}$ and $0.1 \mathrm{~Hz}$, and a larger increase between $0.1 \mathrm{~Hz}$ and $10 \mathrm{~Hz}$. It is the authors' understanding that such an increase in high frequency energy indicates a transfer from large scale to smaller scale turbulence (from various general sources on turbulence, eg. Bradshaw [3]). The w component data, however show that the spectra for vertical turbulence are significantly reduced in energy for frequencies between $0.001 \mathrm{~Hz}$ and $1 \mathrm{~Hz}$, and increased between $1 \mathrm{~Hz}$ and $10 \mathrm{~Hz}$.

Several studies have been carried out to examine the turbulence experienced by moving road vehicles, including by Watkins and Saunders [4, 5]. They made measurements from moving and stationary vehicles on open roads with few obstructions, and roads with significant housing or trees by the roadside, and found that typical longitudinal turbulence intensities varied from $2.5 \%$ to $5 \%$, and lateral intensities from $2 \%$ to $10 \%$. In both cases the surrounding countryside was open and flat.

Modelling the real world in a wind tunnel is difficult (Watkins and Saunders [5]). The larger length scales experienced in the real world, that can be said to have a defined effect on road vehicles (ie. micrometeorological phenomena such as gusts and wind turbulence) tend to 
Copyright @ 2006 SAE International. This paper is posted on this site with permission from SAE International, and is for viewing only. Further distribution and use of this paper is not permitted withoul permission from $S A E$.

be of the same order as the vehicle size, or bigger. Close to the ground, the atmospheric boundary layer has a sheared velocity profile. This means that for a vehicle moving at constant speed in a crosswind, there will be a variation in the total resultant wind speed and direction between ground level, where the ambient wind speed is at its lowest, and the roof of the vehicle. Passive grid turbulence therefore does not accurately represent the complete real world.

However, there is some evidence for dividing the micrometeorological scale further. Bearman [6] states in his review of the effects of turbulence on bluff bodies that if the length scale is large, in comparison to the body, then it is seen as a correlated unsteady mean flow of varying amplitude and dimension. If it is small, it will tend to decay rapidly over the length of the body, although it will also be distorted by the streamline curvature around the body. Smaller length scales may affect the mean flow field around the body, and therefore the mean body forces such as lift and drag.

It may therefore be that although grid generated turbulence is not completely representative of the real world, it still has a part to play in the development of road vehicles, as a device to introduce the smaller scale turbulence that is present in the real world in some form.

Some study has been made of comparisons between wind tunnel data using grids and real world drag reduction. Watkins [7] looked at measurements made of the drag reduction from using a spoiler on a lorry cab in the wind tunnel and compared them to results gained from on road testing. Although Watkins showed that the two sets of results did not match, the method used to measure the drag of the vehicles on the road gave a significant scatter, making the results difficult to interpret.

Wiedemann [8] looked at the effect of turbulence on the "effective Reynolds number" for a simple Reynolds sweep experiment on a car-like body in an open jet wind tunnel. The results gave the drag of the vehicle as being lower with turbulence, although, in the clean tunnel, the drag coefficient $\left(C_{D}\right)$ did not become stable with Reynolds number at high speed. If higher Reynolds numbers were used it is possible from the trend that the drag coefficient with turbulence would cross over the clean $\mathrm{C}_{D}$ and become higher.

In Cogotti's $[9,10]$ tests at full scale, the $C_{D}$ was higher, with the turbulence generating "wings" in use, than for the clean tunnel measurements. However, because the wings introduced a velocity profile, it is stated that it was difficult to identify a reference velocity. Several options are given in the original paper but the point is left open for discussion. In the later work, the question of reference velocity is left unanswered for the case of testing the difference caused by only adding turbulence. The focus is on the simulation of turbulence due to ambient wind, and aiming to simulate this by using a different speed for the rolling road and for the tunnel speed, and using the rolling road speed as a reference.
It seems that, in this case, most of the increase in drag is due to the increased dynamic pressure, rather than the turbulence alone. This seems an accurate depiction of the real world, at least at $0^{\circ}$ yaw, and perhaps it would be possible to optimise a car under this particular condition, although it would be difficult to compare to any other type of test. If the question is the effect of turbulence alone, the experience from this work is that the accuracy of the reference velocity is of significant importance for comparing results at different turbulence levels.

A study was also published by Newnham [11], examining the effect of grid-generated turbulence on front edge radius optimisation. A very simple model was used, designed to have the same width to length to height ratios as a typical $4 \times 4$ vehicle. All the normal detail was removed to give a 1-box shape with a flat floor and roof, flat sides, and a flat rear face. A selection of front sections for varying the leading edge radii on the top and side edges of the front face were constructed. Reynolds sweeps were conducted in the clean tunnel, and comparison made with Cooper [12]. The experiment was then extended by using two different turbulence grids, changing the turbulence intensity in the tunnel from approximately $0.2 \%$ to $1.4 \%$ and $1.5 \%$. It was shown that the increase in turbulence modified the behaviour of the flow over the model, giving a different characteristic curve for the drag coefficient against Reynolds number than in the clean tunnel. It was suggested that the increased turbulence intensity, rather than simply increasing the effective Reynolds number, increases the effective edge radius. The work also discussed the effect of the turbulence on the final drag coefficient of the model. In the original testing, additional turbulence increased the drag coefficient, but in an unpredictable way, with the first, lower turbulence grid producing the highest $C_{D}$ values.

This paper presents an investigation of road vehicle edge radius optimisation techniques in turbulent flows, giving a comparison of results at model scale and full scale, using turbulence generating grids to raise the freestream turbulence intensity in the wind tunnels. At model scale, ten radii are tested in five turbulence levels, and at full scale, seven radii are tested in three turbulence levels.

\section{EXPERIMENTAL METHOD}

\section{MODEL SCALE TUNNEL}

A basic carlike model was developed, based on the aspect ratio of a typical offroad vehicle using the same approach of Newnham [11], but designed to be a basic 2 box shape, with replaceable front sections and a square back. Each front section had a unique radius around the top and side edges, and all were flat on the bottom edge. Following the previous work by Newnham, the main model section had $70 \mathrm{~mm}$ radii on the A-pillars and roof to windscreen edge, which was expected, from the results of the 1-box shape, to ensure that the flow did 
Copyright @ 2006 SAE International. This paper-is posted on this site with permission from SAE International, and is for viewing only.

Further distribution and use of this paper is not permitted withoul permission from $S A E$.

not separate significantly in these areas. The aim was to produce a measurable separation and reattachment effect for the front section and its interaction with the bonnet and windscreen only, and to minimise the chances of separation on the rest of the body. The model is shown in Figure 1. The front section radii varied from $40 \mathrm{~mm}$ to $100 \mathrm{~mm}$ in $10 \mathrm{~mm}$ steps.

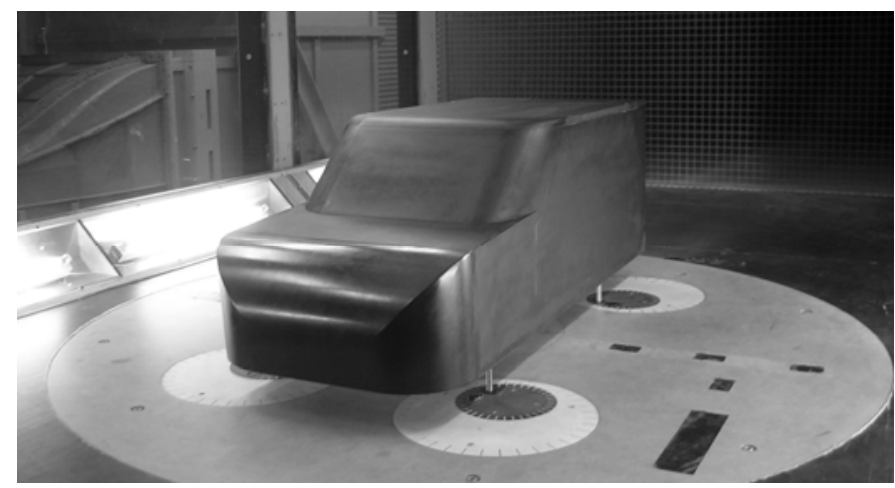

Figure 1 2-box model installed in the Loughborough tunnel

The Loughborough $1.3 \mathrm{~m} * 1.9 \mathrm{~m}$ tunnel was used. The tunnel is an open circuit, closed jet type with a maximum speed of $45 \mathrm{~m} / \mathrm{s}$ with a model installed. Reynolds number sweeps were conducted for each front radius in each turbulence condition by varying the wind tunnel speed between $5 \mathrm{~m} / \mathrm{s}$ and $45 \mathrm{~m} / \mathrm{s}$, in $2.5 \mathrm{~m} / \mathrm{s}$ steps. This gave a range of Reynolds numbers based on the square root of frontal area $\left(\operatorname{Re}_{\mathrm{A}}\right)$ from $1.3^{*} 10^{5}$ to $1.2^{*} 10^{6}$. For the higher turbulence grids, the maximum Reynolds number was reduced by the additional blockage, to $1.0^{*} 10^{6}$ for the $3.5 \%$ grid and $8.3^{*} 10^{5}$ for the $5.1 \%$ grid, because of the increased power requirement. This was the main disadvantage of installing a turbulence generating grid in the working section of the tunnel, where the flow velocity is highest and consequently the loss factor of the grid at its highest. However, this is the only practical way, given that the contraction ratio of $7.4: 1$ precludes installing them in the settling chamber, as the turbulence produced would be significantly damped by the contraction.

The balance used to record data in the model scale tunnel is a 6 component mechanical balance using strain gauges. The overall accuracy of the experiment, based on repeatability tests and the quoted accuracy of the balance, is better than 2 counts of drag $\left(\Delta C_{D}=0.002\right)$ between $15 \mathrm{~m} / \mathrm{s}$ and $47 \mathrm{~m} / \mathrm{s}$ (maximum tunnel speed).

\section{FULL SCALE TUNNEL}

Tests were conducted in the MIRA full scale wind tunnel using the MIRA reference car with a modified front end. The MIRA full scale tunnel is an open circuit, closed jet design with a working section size of $4.4 \mathrm{~m} * 7.9 \mathrm{~m}$ and a maximum speed of $36 \mathrm{~m} / \mathrm{s}$. The balance in the MIRA tunnel is also a 6-component mechanical balance that uses strain gauges. The overall accuracy is quoted as better than 3 counts of drag $\left(\Delta C_{D}=0.003\right)$ at the standard test speed of $28 \mathrm{~m} / \mathrm{s}$. Wooden shapes were used to reduce the radius on the leading edge of the bonnet from $152 \mathrm{~mm}$ to between $25 \mathrm{~mm}$ and $100 \mathrm{~mm}$. The additional pieces extended across the front of the bonnet to the extent of the single radius so as to avoid the complication of the corners where three radii meet. Reynolds sweeps from 9 to $36 \mathrm{~m} / \mathrm{s}$ were used to identify the Reynolds sensitivity of the smaller radii, having previously established that the baseline MIRA reference model was not very sensitive to Reynolds number, in its estate car configuration.

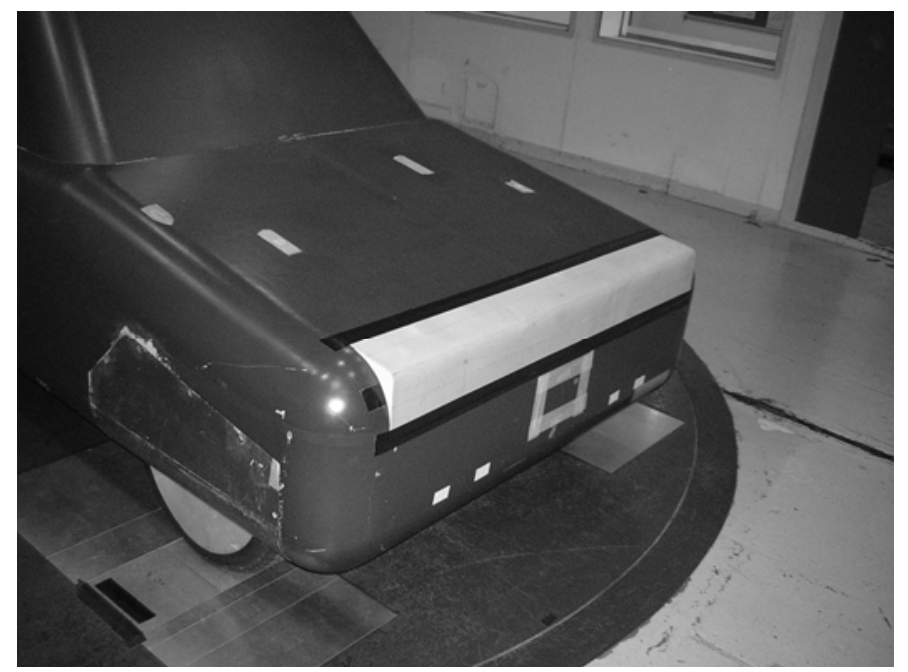

Figure 2 Radius section installed on MIRA full scale reference model

The MIRA reference model is shown in Figure 2 with one of the edge radius extension pieces added.

The Reynolds sweeps were carried out in the unmodified tunnel and with 2 different turbulence grids installed.

\section{TURBULENCE GENERATION AND MEASUREMENT}

In the model tunnel, turbulence was initially generated using standard square grids made of welded steel wire. The grid size was $50 \mathrm{~mm}$ and the wire diameter was $2.41 \mathrm{~mm}$ for the first grid and $3.85 \mathrm{~mm}$ for the second, giving blockage ratios of $9.6 \%$ and $15.4 \%$. The grids were mounted $1.5 \mathrm{~m}$ upstream of the model front face, giving a distance of 30 mesh diameters between the grid and the model (as used by Wiedemann and others [8, 13]). The turbulence was measured using a CTA hotwire system. A vertical line traverse at the model centre gave average turbulence intensities of $1.38 \%$ for the first grid and $1.45 \%$ for the second. The clean tunnel turbulence intensity was measured as $0.18 \%$.

Two further grids were devised, using masking tape on the second wire mesh to raise the blockage ratio. Several schemes were considered and tested using the hotwire to check for uniform turbulence intensity and average flow velocity across the test section. Figure 3 shows the grid pattern chosen. The blockage ratio was 
varied by using two different tape sizes to create the two turbulence grids. Using $25 \mathrm{~mm}$ tape gave a blockage ratio of $37 \%$ and turbulence intensity of $5.13 \%$. Using $12 \mathrm{~mm}$ tape gave a blockage ratio of $24.5 \%$ and a turbulence intensity of $3.41 \%$. The tape scheme was designed to be symmetric about the tunnel floor to avoid the problem of velocity overshoot in the boundary layer.

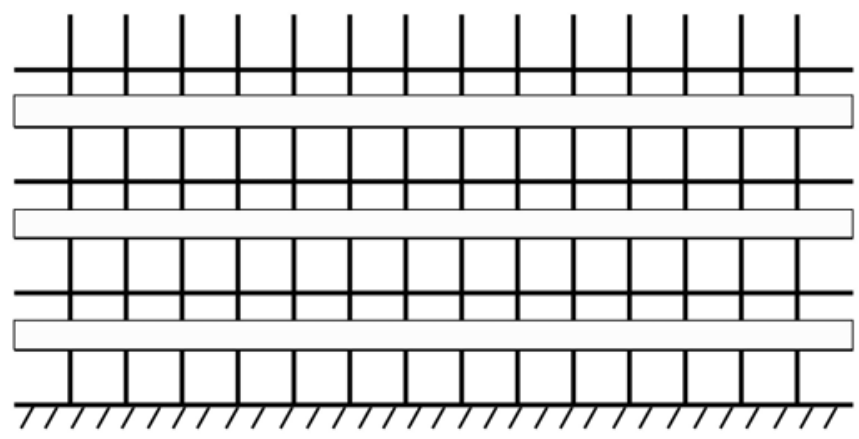

Figure 3 Bottom of grid showing $25 \mathrm{~mm}$ masking tape scheme

The length scales were calculated by fitting the Von Karman spectral model to the measured data, as described by $\mathrm{Li}$ and Melbourne [14]. This gave small length scales for all the grids, as would be expected. The $1.38 \%$ grid had a length scale of $16 \mathrm{~mm}$, the $1.45 \%$ grid $15 \mathrm{~mm}$, the $3.47 \%$ grid $24 \mathrm{~mm}$ and the $5.13 \%$ grid $37 \mathrm{~mm}$. The length scale for the clean tunnel was calculated using this method but is considered of little use, as the value relates to the length of the circuit rather than the size of any turbulent eddies.

In the full scale wind tunnel, turbulence generating grid patterns were installed at the entrance to the contraction on the upstream edge of the honeycomb section flow straightener. The honeycomb in the MIRA tunnel is large, with diamond sections approximately $300 \mathrm{~mm}$ across and $1 \mathrm{~m}$ deep, making it ideal for supporting the large grids, whilst unlikely to significantly reduce the turbulence generated. Several grid schemes were considered, and two schemes were chosen to use for the tests. Both consist of 9 wooden strips mounted vertically at a spacing of $1.4 \mathrm{~m}$ across the honeycomb, with the spacing reducing to $0.7 \mathrm{~m}$ between the pieces of wood at the edges and the walls to give symmetry as before.

The first grid uses $200 \mathrm{~mm}$ strips, and the second $300 \mathrm{~mm}$. Figure 4 shows the second of the grids from behind the model position with the traverse on the main turntable. The first grid was found to generate a turbulence intensity of $3.4 \%$, and the second $4.3 \%$. Hotwire measurements of the standard tunnel showed it to have a turbulence intensity of $1.8 \%$. As a consequence of the practicalities of installing such a large grid, only vertical bars were used, which may have the fortunate result of being more representative of the type of low-level turbulence measured by Richards [2]. Normally grid generated turbulence is expected to decay towards isotropic and homogeneous turbulence, but this is generally claimed for grids with both horizontal and vertical bars. It may be that using vertical bars generates more longitudinal and lateral turbulence and less vertical, but it was not practical to test this. The homogeneity of the turbulence was measured by a traverse at the model location and found to vary by $\pm 0.3 \%$ for both the grids and the clean tunnel. The length scales given using the Von Karman method were $160 \mathrm{~mm}$ for the $3.4 \%$ grid and $165 \mathrm{~mm}$ for the $4.3 \%$ grid. The length scale for the clean tunnel was $250 \mathrm{~mm}$. For the full scale tunnel, the grids are upstream of a 1.3:1 contraction, which would be expected to affect the length scales and intensity.

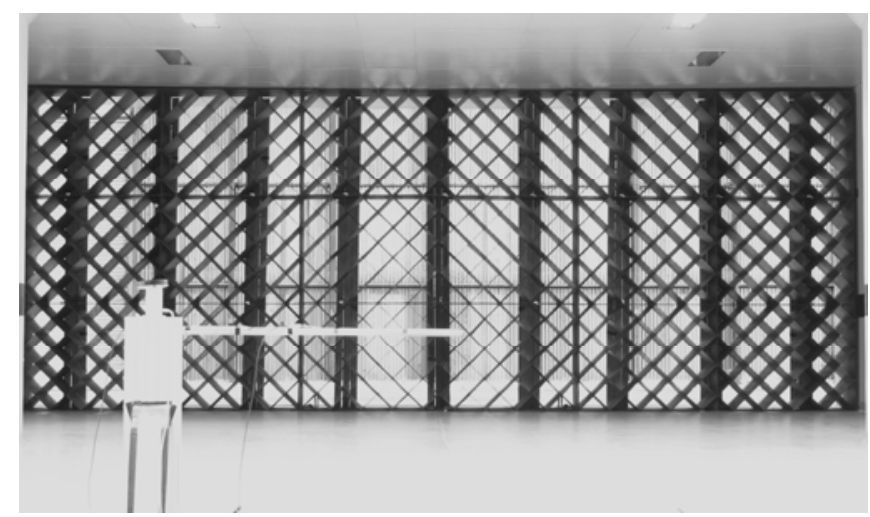

Figure 4 Full scale tunnel grid viewed from the model position

\section{RESULTS AND DISCUSSION}

\section{MODEL SCALE RESULTS}

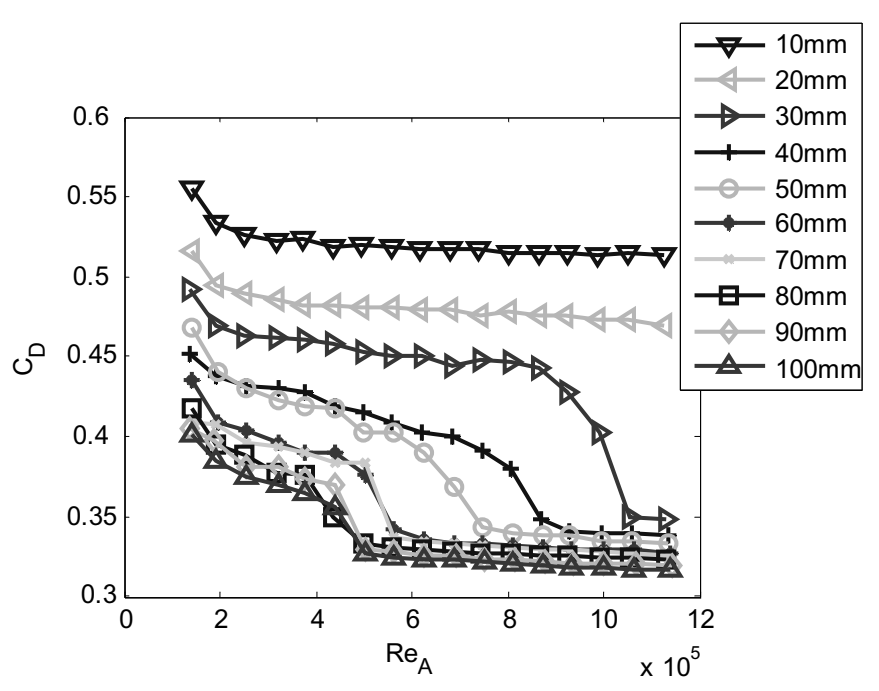

Figure 5 Variation of drag coefficient with Reynolds number based on the square root of frontal area in the clean tunnel (edge radius as a parameter)

Figure 5 shows the results of Reynolds sweeps in the clean tunnel for the drag coefficient $\left(C_{D}\right)$. All but the smallest two front sections undergo a transition from high $C_{D}$ at low Reynolds numbers to low $C_{D}$ at high Reynolds numbers flow. This indicates that there is 
Copyright ( 2006 SAE International. This paper is posted on this site with permission from SAE International, and is for viewing only. Further distribution and use of this paper is not permitted withoul permission from $S A E$.

probably some separation around the radius and over the bonnet for each front section, which disappears at higher Reynolds number. The separation is sustained as the Reynolds number increases and then the $C_{D}$ drops over a small Reynolds number range to a consistent lower value. The fact that all the radii - apart from $10 \mathrm{~mm}$ and $20 \mathrm{~mm}$, which never drop from the initial high drag state - show this characteristic would appear to indicate that there is some additional interaction between the leading edge radius and the windscreen, in comparison with the 1-box model, where only the smaller radii showed this shape. The larger radii on the 1-box model showed a high initial $C_{D}$ which dropped in a smooth curve to an asymptotic consistent $C_{D}$ at higher Reynolds number.

In previous papers the results were non-dimensionalised against the square root of frontal area, but this has not been done here, because it does not aid comparison between the full scale and model scale results. Instead the comparisons focus on the local Reynolds number based on edge radius.

Some of the characteristics of the curves are picked out in Figure 6, which shows the $40 \mathrm{~mm}$ front section on its own for clarity. Based on Cooper's wool tuft testing [12] as well as data on bonnet and windscreen flows as reviewed by Hucho [15], it is believed that in the low Reynolds number flow, the laminar boundary layer separates from the leading radius, probably reattaching down the sides of the model and on the windscreen or the bonnet. As the Reynolds number increases the reattachment point moves along the sides towards the front, reducing the size of the separation bubble on the sides.

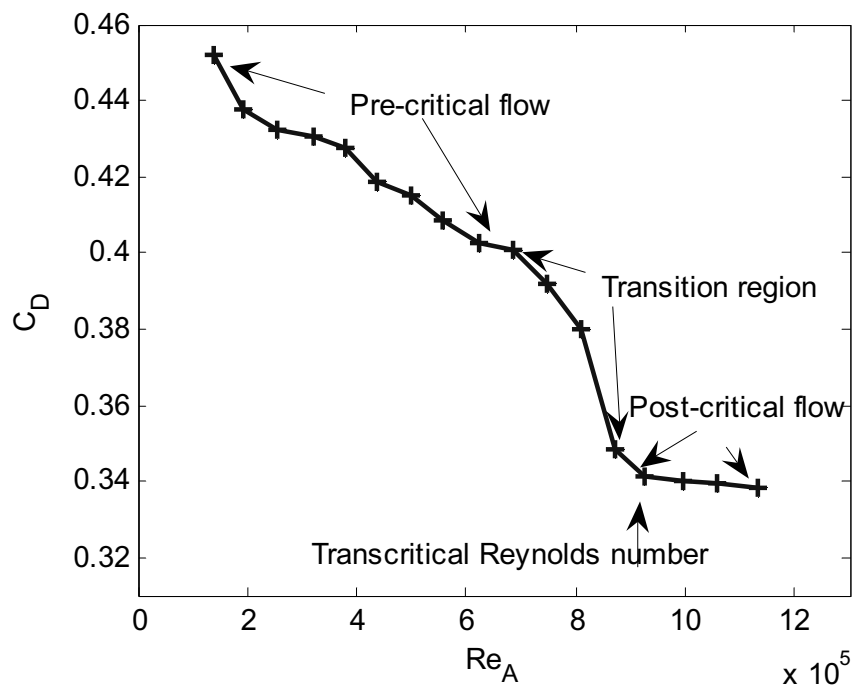

Figure 6 Variation of $C_{D}$ with Reynolds number $R_{A}$ $(\eta=0.104$ only) showing curve characteristics

The reattachment point on the top surface also moves further towards the front of the car, resulting in the gentle reduction in drag coefficient. The separation bubble is believed to be largely stable at this point with a laminar separation and initially laminar free shear layer. At a high enough Reynolds number the boundary layer becomes fully turbulent prior to separation, leading to fully attached flow over the body, possibly with a small separation bubble remaining for the smaller radii, where even a turbulent boundary layer does not stay attached around the radius. It is intended to back up these assumptions by making detailed flow measurements around the radii as part of the further work.

The transcritical Reynolds number as indicated on Figure 6 is defined as the point where $C_{D}$ falls to a low and approximately constant value after the critical Reynolds number. The critical Reynolds number is defined as the point where the separated laminar boundary layer becomes unstable and begins to undergo transition to turbulent flow (Hoerner [16]). While it is possible to identify the transcritical Reynolds number by eye for many of the radii, for consistency and ease of analysis an algorithmic method was defined. A linear best fit of the last points recorded was identified, and then, using a "Piecewise Cubic Hermite Interpolating Polynomial" curve fit, the point where the curve deviates significantly from the line was picked out numerically. The PCHIP fit was used because it produces a result that closely fits the points with little overshoot.

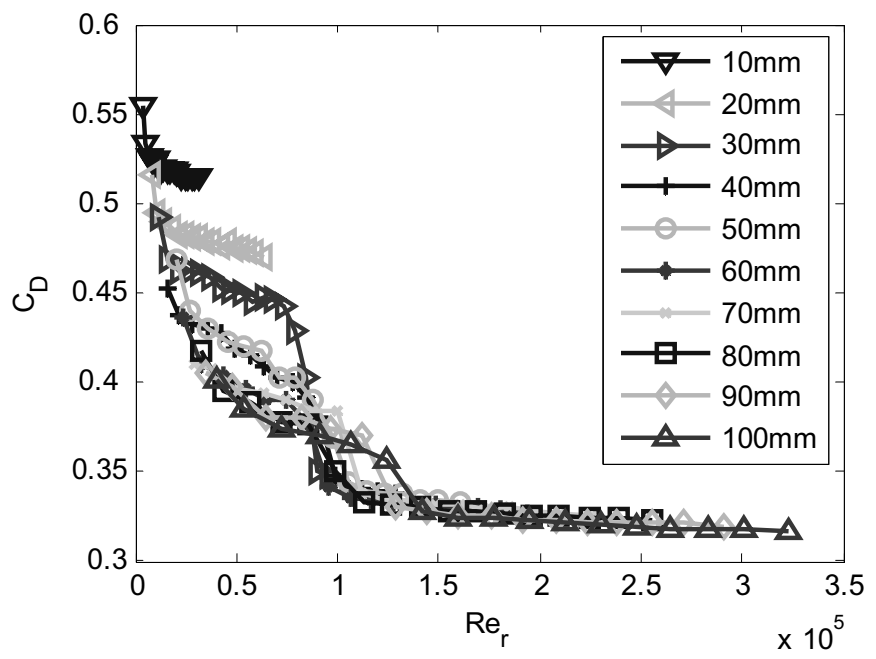

Figure 7 Variation of drag coefficient with Reynolds number based on edge radius in the clean tunnel (edge radius as a parameter)

Figure 7 shows the results with Reynolds number based on edge radius rather than the square root of frontal area. This shows that the transcritical Reynolds numbers based on edge radius are reasonably constant, in agreement with Cooper [12] and Newnham [11]. The figure also shows that the maximum tunnel speed does not result in a high enough local Reynolds number for the $10 \mathrm{~mm}$ and $20 \mathrm{~mm}$ front sections to undergo transition.

The average transcritical Reynolds number based on edge radius, $\mathrm{Re}_{\text {rtcrit }}$ determined from the data in Figure 7 is $1.07^{*} 10^{5}$. This compares well to the previous 
published values, for 1-box models, of $1.30^{*} 10^{5}$ by Cooper [12] and $1.24 * 10^{5}$ by Newnham [11].

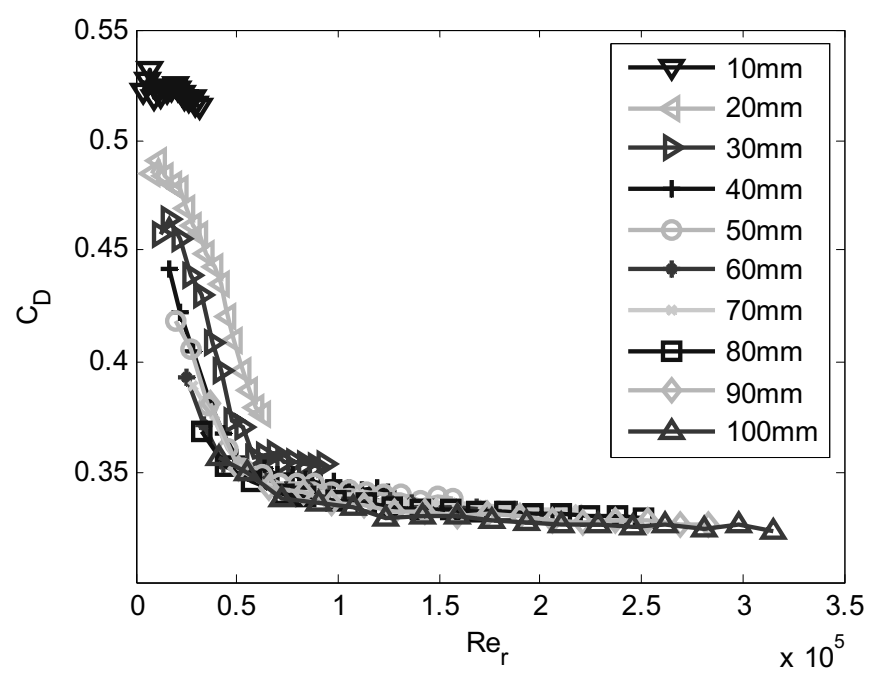

Figure 8 Variation in drag coefficient with Reynolds number based on edge radius for the first turbulence grid (Tu=1.38\%) (edge radius as a parameter)

Newnham [11] found for the 1-box model that when the turbulence intensity was raised to $1.4 \%$ the transcritical Reynolds number was reduced. Figure 8 shows that this is also true for the 2-box model. The transcritical Reynolds number drops to an average of $0.56 * 10^{5}$.

As the constant $\mathrm{Re}_{\text {tcrit }}$ has been reduced, the $20 \mathrm{~mm}$ front section now undergoes transition, although it does not exhibit a full transition to a consistent low $C_{D}$ value. The $10 \mathrm{~mm}$ front still does not undergo transition, because the maximum local Reynolds number is lower than the transcritical value.

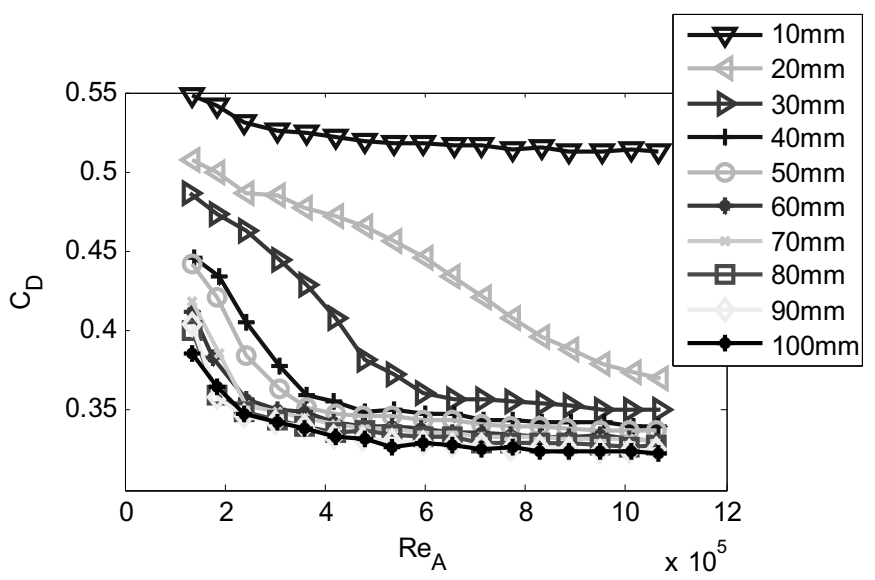

Figure 9 Variation in drag coefficient with Reynolds number based on frontal area for the second turbulence grid (Tu=1.45\%) (edge radius as a parameter)

Figure 9 shows the results for the $1.45 \%$ turbulence grid plotted against Reynolds number based on frontal area. Comparing this figure with Figure 5 shows how the characteristics of the curves have been changed by the additional turbulence. The sharp drops shown for the clean tunnel results are not shown in the turbulent case, and the progression from high $C_{D}$ at low $\operatorname{Re}_{A}$ to low $C_{D}$ at high $\mathrm{Re}_{\mathrm{A}}$ is much smoother.

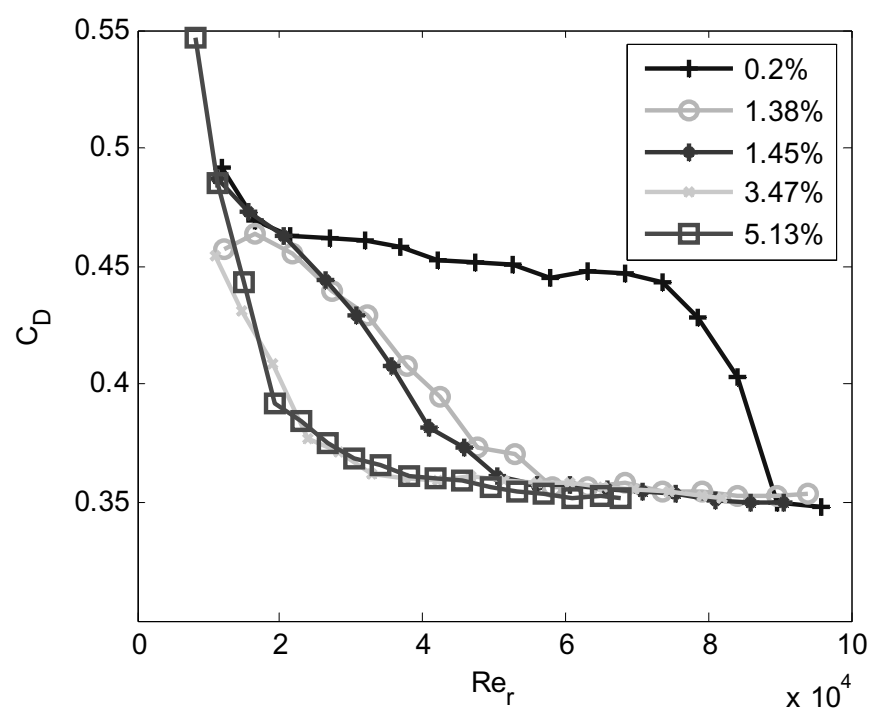

Figure 10 Variation of drag coefficient for the $30 \mathrm{~mm}$ front section only (turbulence intensity as a parameter)

Figure 10 shows the results for the $30 \mathrm{~mm}$ front for all the turbulence conditions tested. This is the smallest radius that underwent transition in the clean tunnel, and it can be seen that the transcritical Reynolds number reduces with increasing turbulence up until the $3.47 \%$ level, after which there is little further reduction. The shape of the curve also changes under the different turbulence conditions. In the clean flow, the transition is very abrupt. With around $1.4 \%$ turbulence, transition is gradual, taking place over around half the Reynolds number range. With higher turbulence, transition occurs very quickly and the curve then drops very slowly towards the minimum value.

The additional freestream turbulence appears to have the effect of increasing the boundary layer growth, inducing the boundary layer to undergo transition to turbulent at a lower Reynolds number. This is backed up by Bearman [6] who in addition states that the freestream turbulence also increases the likelihood of a free shear layer undergoing transition to turbulence.

At low Reynolds numbers the addition of turbulence is seen to reduce the drag coefficient but above the transcritical value, the drag coefficient is higher by a relatively smaller amount. This matches expectations based on the results of Cogotti and Wiedemann [8, 9]. 


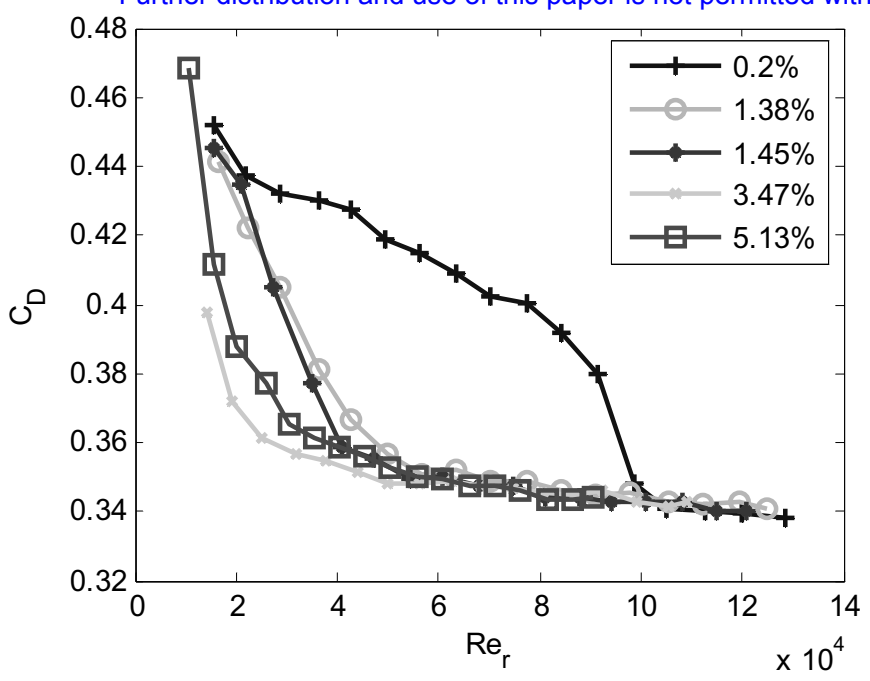

Figure 11 Variation of drag coefficient for the 40mm front section only (turbulence intensity as a parameter)

The results for the $40 \mathrm{~mm}$ front only are shown in Figure 11. The results are similar to Figure 10 , but the larger radius means that all the transcritical Reynolds numbers based on edge radii occur at lower speed, shifting them towards the left hand edge of the figure (although they remain numerically constant). This trend is repeated for all the radii. The trend with turbulence intensity is less clear. For the $30 \mathrm{~mm}$ front section in Figure 10 the turbulence grid results are in rough order from lowest to highest, but in Figure 11 the $3.47 \%$ grid gives the lowest result for drag coefficient at low Reynolds number. The reason for this is not well understood, but it is expected that the turbulence intensity affects different parts of the flow over the model differently. For example, Bearman [6] and others have shown an effect of turbulence on base drag, which has not been investigated here.

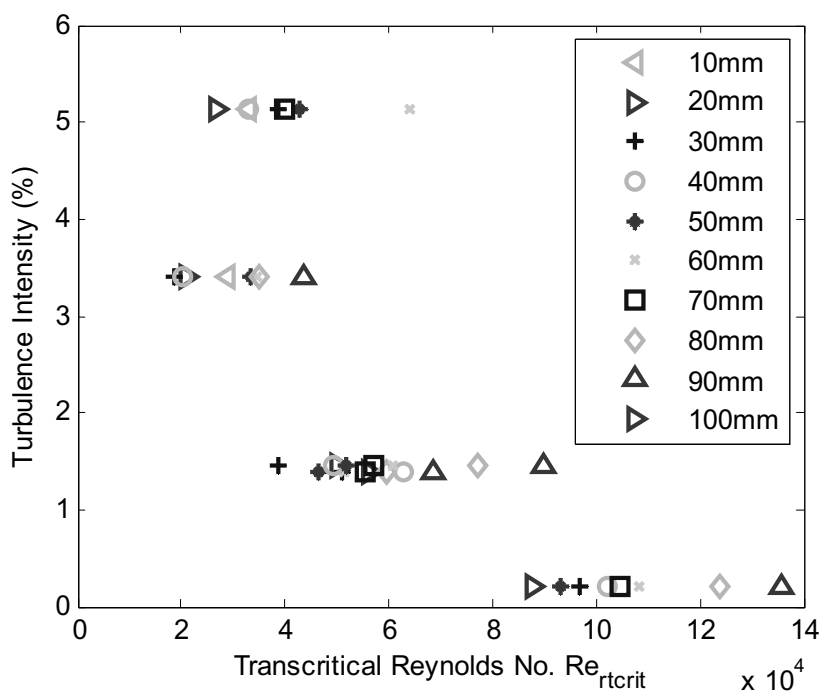

Figure 12 Variation in transcritical Reynolds number with turbulence intensity ( $\eta$ as a parameter)

The transcritical Reynolds numbers for all the front sections that show a clear transition point are shown in Figure 12, replotted to show how $\mathrm{Re}_{\text {tcrit }}$ varies with turbulence intensity. The figure shows that there is a large difference between the results for $0.2 \%$ turbulence and $1.4 \%$ turbulence, and then a smaller difference to $3.4 \%$ turbulence, and almost no difference to $5.1 \%$.

The graph indicates that the average transcritical Reynolds number begins to rise between $3.4 \%$ and $5.1 \%$ turbulence, suggesting that, for the range of intensities tested, there may be a minimum value of $\mathrm{Re}_{\text {rtcrit }}$ at model scale.

The post-critical drag coefficients, at the highest Reynolds number tested, show that the drag with turbulence is generally higher than without. Figure 13 shows the variation in post-critical drag at the highest Reynolds number tested for the $5.1 \%$ turbulence grid. Only the $60 \mathrm{~mm}$ front radius and above are shown, because they are the only ones where measurements of the post-critical condition were taken at the same Reynolds number based on the square root of frontal area.

The post-critical $C_{D}$ is consistently lower in the clean tunnel for any given radius, and almost always highest in the highest turbulence case. However, the $1.38 \%$ turbulence grid produces a very large rise, and then between $1.38 \%$ and $1.45 \%$ there is a large drop. This large difference is not well understood, because the length scales $(15 \mathrm{~mm}$ and $16 \mathrm{~mm})$ are also quite similar. There could be some effect on the base drag, as this has been noted by Bearman[6] and others. In general, turbulence does seem to increase the drag coefficient, as expected from Cogotti's results[9], but these results do not provide a predictable trend.

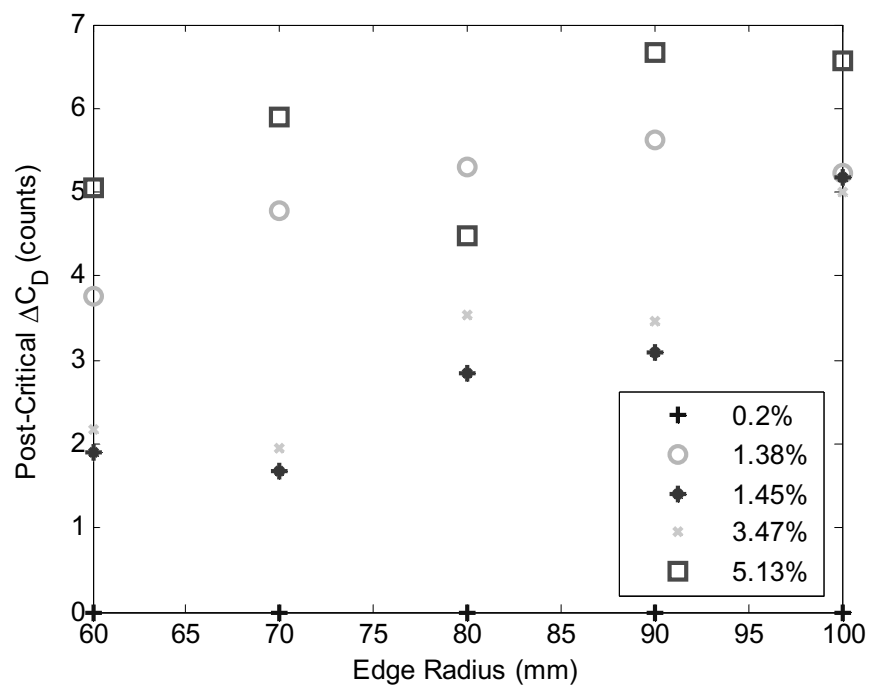

Figure 13 Change in post-critical $C_{D}$ relative to $T u=0.2 \%$ with edge radius at $\operatorname{Re}_{A}=8 * 10^{5}$ (Turbulence case as a parameter)

\section{FULL SCALE RESULTS}

Figure 14 shows the $C_{D}$ results for all radii against Reynolds number based on the square root of frontal 
Copyright ( 2006 SAE International. This paper is posted on this site with permission from SAE International, and is for viewing only. Further distribution and use of this paper is not permitted withoul permission from $\mathrm{SA}^{3} \mathrm{E}$.

area, as plotting in this form allows the characteristic shapes to be more clearly identified. As expected, the smaller radii results are dependent on Reynolds number, with less variation in $C_{D}$ than in the model scale tunnel. The MIRA reference model is different and also the radius was only changed for one of the leading edges. These results are similar to the results for the $1.45 \%$ turbulence results (Figure 9) at model scale, in terms of the transcritical Reynolds numbers and general shape of the curves. Since the turbulence intensity is slightly higher at full scale, the transcritical Reynolds numbers are lower, and the pre-critical flow less evident.

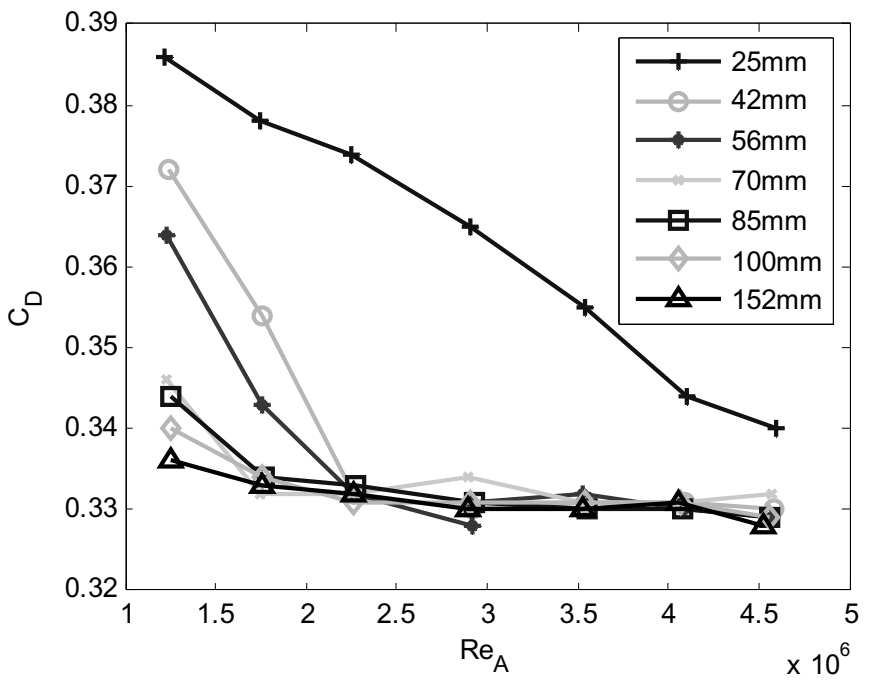

Figure 14 Variation of drag coefficient with Reynolds number for the unmodified full scale tunnel (edge radius as a parameter)

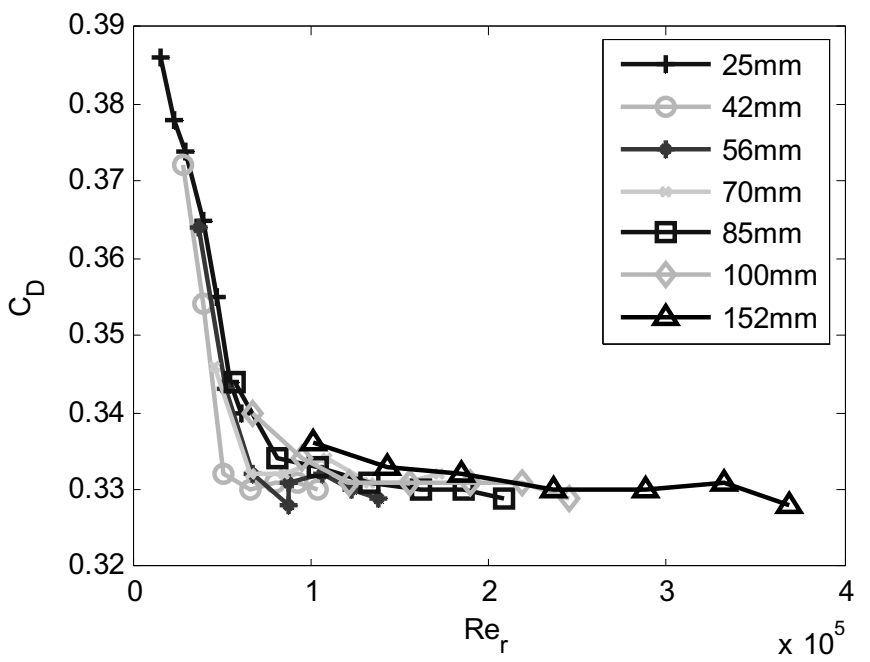

Figure 15 Variation of drag coefficient with Reynolds number based on edge radius in the unmodified full scale tunnel (edge radius as a parameter)

As in the model scale, Figure 15 shows the results replotted against $\mathrm{Re}_{\mathrm{r}}$, and it is clear that they are similar in shape to Figure 8 , but with much less variation in $C_{D}$. The range of Reynolds number tested is larger overall, but the smallest radius does not show fully post-critical flow, and the largest does not enter the transition region at the low end. This was because the wind speed range is more restricted at full scale, to between $9.5 \mathrm{~m} / \mathrm{s}$ and $36.0 \mathrm{~m} / \mathrm{s}$. There is still a clear demarcation between the transition region and the post-critical flow.

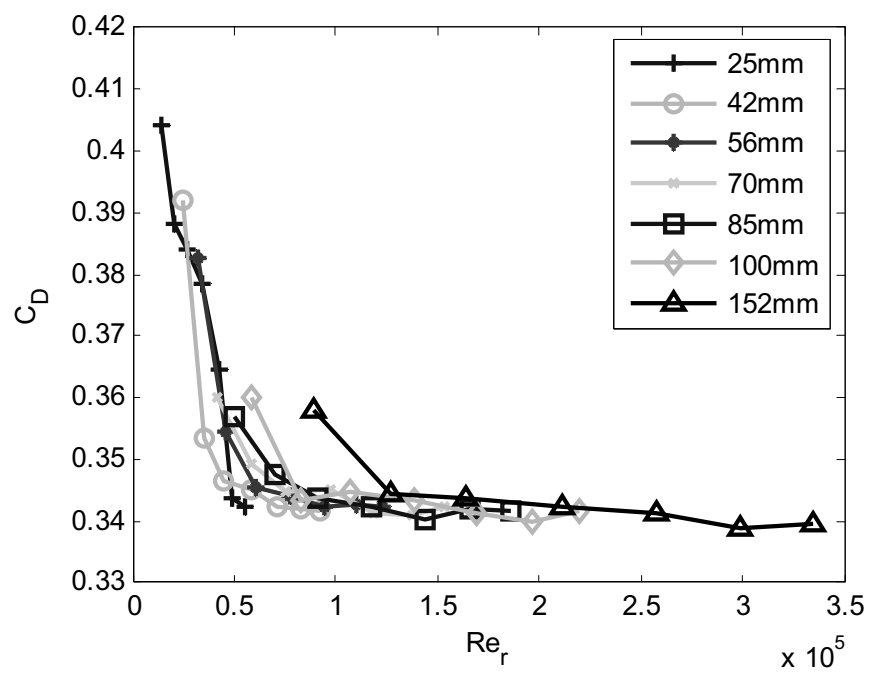

Figure 16 Variation of drag coefficient with Reynolds number based on edge radius for the 3.4\% turbulence grid (edge radius as a parameter)

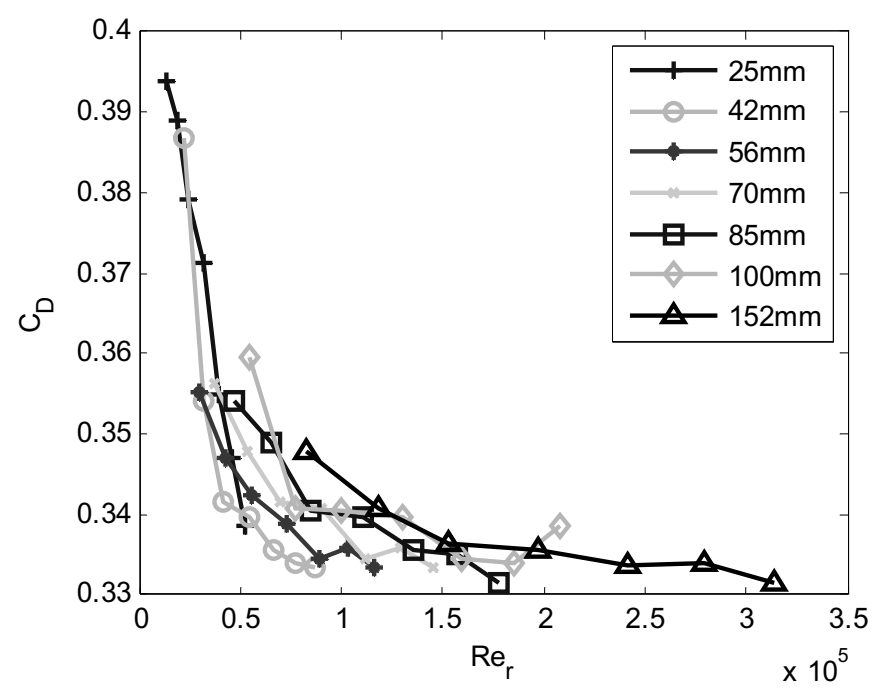

Figure 17 Variation of drag coefficient with Reynolds number based on edge radius for the $4.3 \%$ turbulence grid (edge radius as a parameter)

With the turbulence grids installed, the turbulence intensity was similar to that for the $3^{\text {rd }}$ and $4^{\text {th }}$ grids in the model scale tunnel. Figure 16 and Figure 17 show the results for the turbulence grids against Reynolds number $\mathrm{Re}_{\mathrm{r}}$. As could be expected from the model scale results, there is some reduction in the transcritical Reynolds number, but not a dramatic difference compared to Figure 15. Ignoring the two largest radii, which do not show a convincing transition region (only the lowest point, where the tunnel speed is at its least stable, is at all higher than the others), Figure 16 shows a very tight 
group of trancritical Reynolds numbers for the various radii, while the spread is larger for Figure 17.

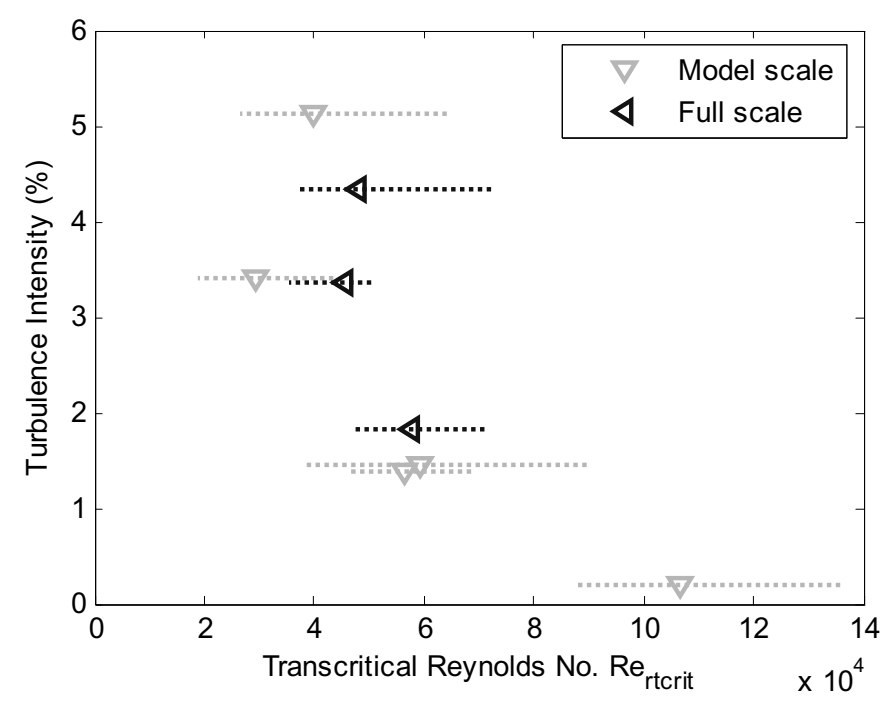

Figure 18 Variation in average transcritical Reynolds number with turbulence intensity for both wind tunnels

The transcritical Reynolds numbers were extracted from the full scale data using the same method as described earlier. Figure 18 shows the average results at each turbulence level plotted against turbulence intensity. The dotted lines indicate the full spread of the results. It is immediately clear that there is good agreement between the model scale and full scale results. The transcritical Reynolds number again reaches a minimum and then rises slightly at the highest turbulence intensity.

It is worth noting that only 5 of the 7 radii tested at full scale showed convincing transcritical Reynolds number, and it is suggested that a useful extension to this work would be to increase the number of radii tested in the range that do go through the transcritical Reynolds number within the speed range tested.

Figure 19 shows a comparison of the results for the $42 \mathrm{~mm}$ front section only. There is some variation in the shape of the curve between the unmodified tunnel and the turbulence grid results, in a similar manner to the difference between the results for the $\sim 1.4 \%$ turbulence grids and the higher turbulence grids at model scale (Figure 11).

In order to ensure correct comparison between the $C_{D}$ values, the reference pitot was calibrated against the tunnel centreline with and without the turbulence grids installed, and the results were corrected based on this calibration. The results show that raising the turbulence level above the clean tunnel level did increase the drag, but going between $3.4 \%$ and $4.3 \%$ actually reduced it again. The difference between the baseline and the $3.4 \%$ grid result is an increase of 10 counts of drag. The $4.3 \%$ grid then reduces the drag by as much as 8 counts from that level, bringing it very close to the clean tunnel result. The reasons for this are not well understood, but could be as a result of changes in the base pressure, which is known to be affected by turbulence (eg. Bearman [6]).

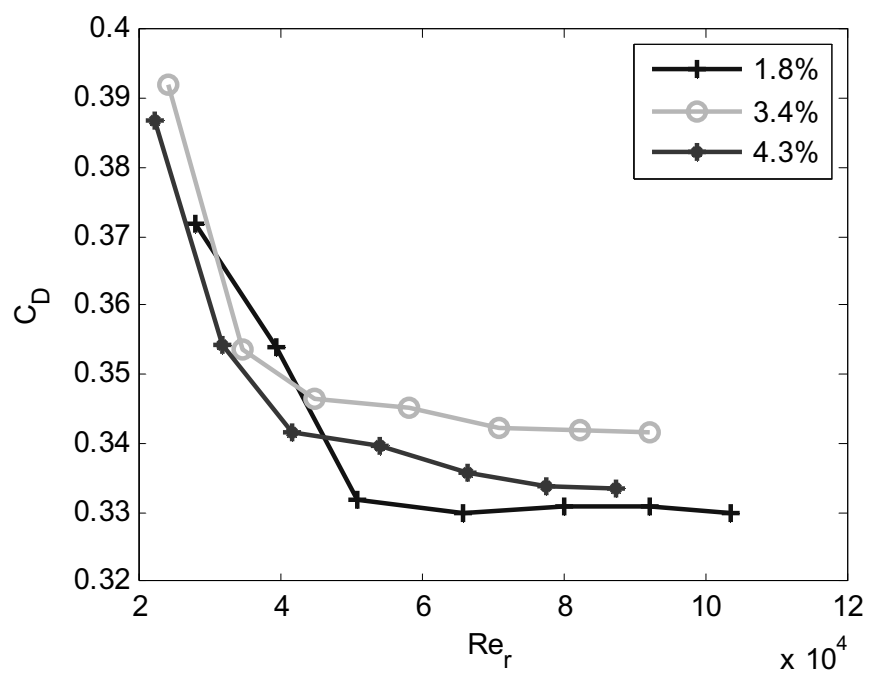

Figure 19 Variation of drag coefficient with Reynolds number, $42 \mathrm{~mm}$ front radius only (turbulence intensity as a parameter)

\section{FURTHER WORK}

It is intended to extend this work to cover the effect of turbulence on rear shaping, making balance measurements on a model with an adjustable backlight angle and comparing the results at different levels of turbulence, and with previous studies.

It is also intended to make further measurements on the current models, looking at the flowfield around the radii with a hotwire and with an LDA system. The state of the boundary layer and its thickness will be examined for several radii at significant Reynolds numbers.

\section{CONCLUSION}

The effect of turbulence on the aerodynamic drag of a simple 2-box shape with different front edge radii has been investigated for a basic model and a generic car shape at full scale. Both model and full scale tests show a significant reduction in the transcritical Reynolds number for a given edge radius with increasing turbulence.

The model tests show that overall drag coefficient is noticeably increased with the introduction of a small level of turbulence and increases slightly with higher turbulence. The raised turbulence level also caused the shape of the Reynolds sweep curve to change. In the very low turbulence of the clean tunnel, the drag coefficient persisted at a high value up to a higher Reynolds number, followed by an abrupt collapse. When the turbulence intensity was increased, the transition to low drag post-critical flow was much more gradual.

The full scale results showed a good correlation with the model scale results for the variation of transcritical 
Reynolds number based on edge radius with turbulence intensity. The drag coefficient was also higher with the grids installed, although the high turbulence grid produced a lower $C_{D}$ than the lower turbulence grid.

\section{ACKNOWLEDGMENTS}

The first author would like to thank the MIRA technicians for their support and patience, and the technicians at Loughborough University for their help in building wind tunnel models and general support of the wind tunnel test program. Special thanks to Rob Hunter, Keith Coulthard, Peter Stinchcombe, and Dave Wain. The author would also like to thank Jenny Yates for her assistance with some of the model scale work as part of her undergraduate project, and Simon Watkins for useful suggestions on generating higher levels of turbulence in the model tunnel.

\section{REFERENCES}

1. Characteristics of atmospheric turbulence near the ground. Part II: single point data for strong winds (neutral atmosphere). ESDU 85020.

2. P. J. Richards, R. P. Hoxey and J. L. Short. Spectral models for the neutral atmospheric surface layer. J.Wind Eng.Ind.Aerodyn. Vol. 87, Iss. 2-3, pp.167185,2000

3. P. Bradshaw. An Introduction to Turbulence and its Measurement. 1971

4. S. Watkins, J. W. Saunders and P. H. Hoffmann. Turbulence experienced by moving vehicles. Part I. Introduction and turbulence intensity. J.Wind Eng.Ind.Aerodyn. Vol. 57, Iss. 1, pp.1-17, 1995

5. Simon Watkins and Jeff Saunders. Review of the wind conditions experienced by a moving vehicle. SAE Paper 981182 pp.211-218, 1998

6. P. W. Bearman and T. Morel. Effect of Free Stream Turbulence on the Flow Around Bluff Bodies. Prog. Aerospace Sci. Vol. 20, pp.97-123, 1983

7. S. Watkins, J. W. Saunders and P. H. Hoffmann. Comparison of road and wind-tunnel drag reductions for commercial vehicles. J.Wind Eng.Ind.Aerodyn. Vol. 49, Iss. 1-3, pp.411-420, 1993

8. J. Wiedemann. Turbulence Manipulation to Increase Effective Reynolds Number in Vehicle Aerodynamics. AIAA Journal Vol. 27, Iss. 6, pp.763769, 1989

9. A. Cogotti. The Evolution of the Testing Environment in the Pininfarina Wind Tunnel: The new Turbulence Generation System. Proceedings of the Fifth
International Colloquium on Bluff Aerodynamics and Applications, 2003

10. A. Cogotti. Update on the Pininfarina "Turbulence Generation System" and its effects on the car Aerodynamics and Aeroacoustics. 2004-01-0807. SAE Technical Paper Series 2004

11. P. S. Newnham, M. A. Passmore and A. Baxendale. An experiment to investigate the influence of free stream turbulence on edge radius optimisation. 5th MIRA International Vehicle Aerodynamics Conference 2004

12. K. R. Cooper. The Effect of Front-Edge Rounding and Rear-Edge Shaping on the Aerodynamic Drag of Bluff Vehicles in Ground Proximity. 850288. SAE Transactions pp.2.727-2.757, 1986

13. Mohamed Gad-el-Hak and Stanley Corrsin. Measurements of the nearly isotropic turbulence behind a uniform jet grid. J. Fluid Mech. Vol. 62, Iss. 1, pp.115-143, 1974

14. Q. S. Li and W. H. Melbourne. The effect of largescale turbulence on pressure fluctuations in separated and reattaching flows. J.Wind Eng.Ind.Aerodyn. Vol. 83, pp. 159-169, 1999

15. Hucho, W-H. et al. Aerodynamics of Road Vehicles (Fourth Edition). 1998

16. S. F. Hoerner. Fluid-Dynamic Drag. 1958

\section{CONTACT}

Phil Newnham

Research Student

Dept. of Aeronautical and Automotive Engineering

Loughborough University

Loughborough

LEICS LE11 3TU

UK

p.s.newnham@lboro.ac.uk

\section{DEFINITIONS, ACRONYMS, ABBREVIATIONS}

$\eta \quad$ non-dimensional edge radius

A frontal area

$C_{D} \quad$ drag coefficient

$r \quad$ front edge radius

$\mathrm{Re}_{\mathrm{A}} \quad$ Reynolds number based on the square root of frontal area

$\mathrm{Re}_{\mathrm{r}} \quad$ Reynolds number based on front edge radius

$\mathrm{Re}_{\text {rtcrit }}$ transcritical Reynolds number based on front edge radius

Tu turbulence intensity 